\title{
El reforzamiento de la identidad cooperativa a través de la formación: un elemento a considerar por el movimiento cooperativo
}

(The strengthening of cooperative identity through training: an element to be considered by the cooperative movement)

\author{
Gonzalo Martínez Etxeberria' \\ Universidad de Deusto (España)
}

Sumario: 1. Introducción. 2. ¿Qué es y en qué consiste la identidad cooperativa? 3. Un breve análisis histórico de la evolución en la construcción de una identidad cooperativa reconocible. 4. Los peligros a los que se enfrenta el movimiento cooperativo desde el punto de vista de su identidad. 4.1 Los peligros a los que se enfrentan las cooperativas en los países con economías de mercado. 4.2. Los peligros a los que se enfrentan las cooperativas en los países con economías intervencionistas. 5. La educación y la formación cooperativa: una realidad necesaria en la consolidación de una identidad cooperativa para el S.XXI. 5.1 La formación en valores cooperativos. 5.2 La formación específica relacionada con la gestión de la cooperativa atendiendo a su especial naturaleza. 5.3 La formación técnica específica en las cooperativas atendiendo a sus necesidades productivas. 6. Conclusiones. 7. Bibliografía.

Summary: 1. Introduction. 2. What is the cooperative identity? 3. A historical analysis of the evolution in the construction of a recognizable cooperative identity. 4 . The dangers that the cooperative movement faces from the point of view of its identity. 4.1 The dangers faced by cooperatives in countries with market economies. 4.2. The dangers faced by cooperatives in countries with interventionist economies. 5. Cooperative education and training: a necessary reality in the consolidation of a cooperative identity for the 21 st century. 5.1 Training in cooperative values. 5.2 Specific training related to the management of the cooperative, taking into account its special na-

1 Profesor en la Facultad de Derecho e investigador de grupo «Cooperativismo, Fiscalidad, Fomento, Relaciones Laborales y Protección Social» de la Universidad de Deusto. Email: gonzalo.metxeberria@deusto.es. 
ture. 5.3 Specific technical training in cooperatives attending to their productive needs. 6 . Conclusions. 7. Bibliography.

Resumen: Las cooperativas modernas, hunden sus raíces en unos valores y principios cooperativos que fijan su identidad. En los tiempos actuales y habida cuenta de los profundos cambios a los que el mundo se está viendo sometido, la formación cooperativa se muestra como una herramienta esencial para consolidar dicha original identidad.

Palabras clave: Cooperativas, Identidad cooperativa, Formación cooperativa, Movimiento cooperativo.

Abstract: Modern cooperatives have their roots in cooperative values and principles that establish their identity. In current times and given the profound changes to which the world is being subjected, cooperative training is shown as an essential tool to consolidate this identity.

Keywords: Cooperatives, Identity, Cooperative movement. 


\section{Introducción}

El contexto de crisis económica de los últimos años, ha condicionado la forma de actuar en el mercado de los diferentes tipos de sociedades mercantiles, entre ellas las sociedades cooperativas ${ }^{2}$. En una realidad de mercado tan globalizada y competitiva como la actual, las sociedades cooperativas, deben profundizar en el afianzamiento de su identidad cooperativa, de cara a que las sociedades en las que desarrollan sus actividades, venden sus productos y ofertan sus servicios sean conscientes de los elementos diferenciadores que como sociedades mercantiles cooperativas que son les asisten. Por ello, los valores cooperativos a los que aspiran y los principios cooperativos de los que se dotan para alcanzarlos, deben ser reforzados y actualizados hacia adentro y explicados hacia afuera, siendo el medio idóneo para ello y en la actualidad la educación y la formación.

La finalidad última de todo ello no ha de ser otra que la de poner un grano de arena en el desierto de un mercado cada vez más complejo e internacionalizado, tratando de conseguir convertir dichos valores cooperativos, en valores sociales que trasciendan de la propia cooperativa, tratando de producir de esta forma sinergias sociedadcooperativa y viceversa, que permitan a las cooperativas seguir existiendo y progresando en el mundo actual y en los venideros.

\section{2. ¿Qué es y en qué consiste la identidad cooperativa?}

A la hora de desgranar qué hemos de entender por identidad cooperativa a lo largo de este trabajo, conviene precisar los términos, pues no son pocas las veces que éstos son utilizados o percibidos de formas muy diversas. Por ello, y con un afán metodológico claro, el inicio de esta aproximación terminológica no debe ser otro que el de acercarse a la realidad de lo que es y significa la identidad desde un punto de vista estrictamente etimológico, para a continuación completar su significado una vez añadido el calificativo de "cooperativa».

Siguiendo las definiciones recogidas por el diccionario de la Real Academia Española 3 (en adelante RAE), y más concretamente las acepciones segunda y tercera del concepto de identidad, hemos de entender por tal, «el conjunto de rasgos propios de un individuo o de una

2 Gaminde Egia, Eba (2018, 33-69)

3 Diccionario de la Real Academia española. Edición actualizada, año 2018. 
colectividad que los caracterizan frente a los demás (acepción segunda) y conciencia que una persona tiene de ser ella misma y distinta a las demás» (acepción tercera).

De igual forma y en lo que al calificativo de «cooperativa» se refiere, y siguiendo su referencia etimológica a través de lo recogido en la acepción segunda del diccionario de la RAE, entenderemos desde este instante por "cooperativa», sociedad cooperativa. Dicho así, la base de esta investigación no es otra que la de profundizar en el análisis de la identidad de la cooperativa, para a partir de ahí tratar de comprenderla en aras de aportar propuestas para reforzarla.

Por ello, entenderemos, que la sociedad cooperativa es una sociedad constituida por personas que se asocian libremente, en régimen de libre adhesión y baja voluntaria, para la realización de actividades empresariales, encaminadas a satisfacer sus necesidades y aspiraciones económicas y sociales, con estructura y funcionamiento democrático. Este tipo sociedades cooperativas pueden ser útiles para empresas que tengan por objeto y finalidad la colaboración de sus socios para el logro de un objetivo común, sobre la base de la ayuda mutua y de la creación de un patrimonio común irrepartible.

Si nos atenemos a las definiciones legales que recogen tanto la Ley vasca ${ }^{4}$ como la española ${ }^{5}$, la definición legal de sociedad cooperativa se completa en cada caso con otras precisiones establecidas por los respectivos legisladores. Así, en el caso de la definición de sociedad cooperativa que establece la normativa autonómica vasca, a día de hoy vigente ${ }^{6}$, en su artículo primero, la sociedad cooperativa es "aquella sociedad que desarrolla una empresa que tiene por objeto prioritario la promoción de las actividades económicas y sociales de sus miembros y la satisfacción de sus necesidades con la participación activa de los mismos, observando los principios del cooperativismo y atendiendo a la comunidad de su entorno (párrafo $1 .^{\circ}$ )». A lo que añade en sus párrafos siguientes que «la cooperativa deberá ajustar su estructura y funcionamiento a los principios cooperativos, que serán aplicados en el marco de la presente Ley. Dentro de ésta actuará con plena autonomía e independencia respecto de cualesquiera organizaciones y entidades,

${ }^{4}$ Ley 4/1993, de 24 de junio, de Cooperativas de Euskadi, publicada en el BOPV n. ${ }^{\circ} 135$, de 19 de julio de 1993.

5 Ley 27/1999, de 16 de julio, de Cooperativas, publicada en el BOE n. ${ }^{\circ} 170$, de 19 de julio de 1999.

6 El procedimiento legislativo para la aprobación de una nueva Ley vasca de cooperativas está a día de hoy en marcha, con lo que, desconocemos si el legislador pueda identificar la necesidad de modificar de algún modo esta definición. 
públicas o privadas» (párrafo segundo), para concluir en el párrafo tercero que «las cooperativas pueden realizar cualquier actividad económica o social, salvo expresa prohibición legal basada en la incompatibilidad con las exigencias y principios básicos del cooperativismo».

En el caso de la legislación española, y más concretamente en los párrafos primero y segundo del artículo primero, que es donde se aborda el concepto, (los siguientes párrafos hacen referencia a otras cuestiones como su denominación o las diferentes formas que pueden éstas adoptar), la sociedad cooperativa se define como «una sociedad constituida por personas que se asocian, en régimen de libre adhesión y baja voluntaria, para la realización de actividades empresariales, encaminadas a satisfacer sus necesidades y aspiraciones económicas y sociales, con estructura y funcionamiento democrático, conforme a los principios formulados por la alianza cooperativa internacional, en los términos resultantes de la presente Ley» (párrafo primero), para a continuación precisar en el párrafo segundo que, «cualquier actividad económica lícita podrá ser organizada y desarrollada mediante una sociedad constituida al amparo de la presente Ley».

Estas definiciones legales, no son sino dos ejemplos, de cómo el legislador estatal o autonómico en el caso español y en su caso, precisa, completa y pone el punto de mira en los legítimos intereses que le son propios como legislador a la hora de perfeccionar el significado legal de esta realidad. Con lo cual, y en el caso que nos ocupa, encontramos en el ordenamiento jurídico español tantas definiciones como normativas autonómicas existen ${ }^{7}$, si bien subyace a todas ellas una serie de

7 Valgan de ejemplo las siguientes normas autonómicas y las definiciones conceptuales que acompañan sus textos habitualmente en sus primeros artículos, en los que bajo las premisas comunes a todas ellas y que aludía en el texto cada una fija su impronta con algún elemento característico diferenciador del resto. Así:

Andalucía: Ley 14/2011, de 23 de diciembre, de sociedades cooperativas andaluzas, publicada en el $B O E$ n. ${ }^{\circ} 17$ de 20 de enero de 2012, en cuyo segundo artículo fija la realidad de las cooperativas andaluzas como «las sociedades cooperativas andaluzas son empresas organizadas y gestionadas democráticamente que realizan su actividad de forma responsable y solidaria con la comunidad y en las que sus miembros, además de participar en el capital, lo hacen también en la actividad societaria prestando su trabajo, satisfaciendo su consumo o valiéndose de sus servicios para añadir valor a su propia actividad empresarial».

Asturias: Ley del Principado de Asturias 4/2010, de 29 de junio, de cooperativas, publicada en el $B O E n{ }^{\circ} 232$ de 24 de septiembre, en cuyo primer artículo párrafo define la cooperativa como "una sociedad constituida por personas físicas o jurídicas que se asocian, en régimen de libre adhesión y baja voluntaria, para la satisfacción conjunta de sus necesidades e intereses socioeconómicos comunes, a través del desarrollo de actividades empresariales y de la adopción de una estructura, funcionamiento y gestión democráticos, siempre con el propósito de mejorar la situación económica y social de sus 
elementos que las hacen reconocibles, tales como, la libre adhesión y voluntaria de sus miembros, el régimen democrático de su funcionamiento, su finalidad social etc... al margen de otros tantos que están ya perfectamente insertados en el imaginario colectivo de la ciudadanía, lo que les permite, poder identificar una sociedad cooperativa y ser capaces de diferenciarlas de otro tipo de formas jurídico-societarias de carácter mercantil como por ejemplo una sociedad anónima o una sociedad limitada.

miembros y de su entorno comunitario». Esta última referencia al propósito social resulta identificadora de las pretensiones del legislador asturiano a la hora de definir la sociedad cooperativa.

Cantabria: Ley 6/2013, de 6 de noviembre, de cooperativas de Cantabria, publicada en el $B O E$ n. ${ }^{\circ} 284$, de 27 de noviembre de 2013, en cuyo artículo segundo define cooperativa como:

1. A los efectos de esta Ley, las cooperativas son sociedades constituidas por personas que se asocian en régimen de libre adhesión y baja voluntaria para satisfacer sus necesidades y aspiraciones económicas y sociales, dotadas de estructura, funcionamiento y gestión democráticos y en las que sus miembros, además de participar en el capital, lo hacen también en la actividad societaria prestando su trabajo, satisfaciendo su consumo o valiéndose de sus servicios, con el propósito de mejorar la situación económica y social de sus miembros y el entorno comunitario.

2. La sociedad cooperativa se ajustará a los principios formulados por la Alianza Cooperativa Internacional, en los términos resultantes de la presente Ley.

3. Cualquier actividad económica y social lícita podrá ser organizada y desarrollada mediante una sociedad cooperativa constituida al amparo de la presente Ley.

Destaca a mi juicio como elemento clarificador, las exigencias formales y materiales que establece para la figura del socio.

Galicia: Ley 5/1998, de 18 de diciembre, de cooperativas de Galicia, publicada en el $B O E \mathrm{n} .{ }^{\circ} 72$ de 25 de marzo de 1999, en cuyo primer artículo la cooperativa queda definida como una sociedad de capital variable que, con estructura y gestión democráticas, en régimen de libre adhesión y baja voluntaria, desarrolla una empresa de propiedad conjunta, a través del ejercicio de actividades socioeconómicas, para prestar servicios y satisfacer necesidades y aspiraciones de sus socios, y en interés por la comunidad, mediante la participación activa de los mismos, distribuyendo los resultados en función de la actividad cooperativizada.

Extremadura: Por el momento la última ley de cooperativas autonómicas aprobada Ley 9/2018, de 30 de octubre de cooperativas de Extremadura, publicada en el $B O E \mathrm{n} .{ }^{\circ} 289$, de 30 de noviembre de 2018, en cuyo artículo inicial define la cooperativa como «La sociedad cooperativa es una sociedad de base mutualista, con personalidad jurídica propia, en la que los socios se unen de forma voluntaria para satisfacer sus necesidades mediante la realización de actividad cooperativizada, realizan aportaciones al capital social y administran democráticamente la empresa, ostentando el derecho esencial a participar en la gestión de los asuntos sociales».

Sobre estas cuestiones resulta de interés Gadea Soler, Enrique $(2015,13-27)$ (2014, 97-111). 
En ese imaginario colectivo ciudadano del que hablo en el párrafo inmediatamente anterior, están ubicados también alguno de los valores cooperativos a las que las sociedades cooperativas aspiran o deben aspirar en el ejercicio de su actuaciones, en busca de sus legítimos fines sociales, así como los principios de actuación para lograrlos, que desde Rochdale hasta nuestro días, y con el importante influjo de la Asociación Cooperativa Internacional (ACI), han pretendido y pretenden ser una guía o una hoja de ruta en el funcionamiento de este tipo de sociedades. Tanta es su importancia, la de la ACl a la hora de hacer de guía en el establecimiento de una serie de principios universalmente reconocidos, que la propia legislación española los identifica en el concepto propio de cooperativa recogido en el artículo primero de su norma ${ }^{8}$.

Esta cuestión resulta trascendental, pues gracias a la $\mathrm{ACl}$ quedan fijados unos marcos de referencia teóricos-formales y para la totalidad del movimiento cooperativo que se precie como tal, siendo este marco, un marco universal y mínimamente exigible para el reconocimiento y la identificación de las cooperativas, y poder de esta forma, tener los criterios adecuados para poder distinguirlas de otras formas jurídicas que potencialmente puedan aprovecharse de sus aspectos más favorables para sus intereses y puedan hacer caso omiso de sus obligaciones y patrones de comportamiento como cooperativas.

Esta precisión conceptual que hace la legislación española para los principios cooperativos, y la referencia a la hora de quedar fijados en relación con los planteamientos que haga en este sentido la $\mathrm{ACl}$, entiendo que es positiva, pues desde la propia norma se establece una referencia homogeneizada de los mismos y en cierta forma dichos principios se erigen en referencia normativizada para las numerosas cooperativas ubicadas en este caso en España.

No ocurre los mismo en la referencia que la Constitución española de $1978^{9}$ lleva a cabo en el artículo $129.2^{10}$ por la cual se establece la exigencia de la promoción por parte de los poderes públicos del cooperativismo, en la que se echa en falta desde mi punto de vista una concreción conceptual de lo que debe ser el tipo de cooperativismo que ha

8 Ibidem, p.3.

9 Constitución Española de 1978, publicada en el BOE n. ${ }^{\circ} 311$, de 29 de diciembre de 1978.

10 Artículo 129.2 de la CE de 1978: «los poderes públicos promoverán eficazmente las diversas formas de participación en la empresa y fomentarán, mediante una legislación adecuada, las sociedades cooperativas. También establecerán los medios que faciliten el acceso de los trabajadores a la propiedad de los medios de producción». 
de ser promocionado por parte de los poderes públicos. Bien es cierto que para el constituyente tal vez resultase inimaginable que una identificación tan clara de las sociedades cooperativas como aquel entonces $^{11}$ se tornara tan compleja y pudiera tener cuarenta años después, los matices sobre su realidad que hoy enmascaran algunas formas jurídicas que cuestionan la idiosincrasia de las auténticas cooperativas como el caso de las "falsas cooperativas» u formas empresariales que operan en nuestros mercados y que no pocas veces confunden a los ciudadanos y consumidores a las que me referiré más adelante.

Lo que es evidente, es que el constituyente identificó como realidades a potenciar por parte de los poderes públicos a las cooperativas, porque de alguna manera deben perseguir finalidades sociales que se identifican con el bien de la comunidad a la escala que sea, local, autonómica o estatal. La cuestión relevante en la actualidad, es qué tipo de sociedades cooperativas han de promoverse desde los poderes públicos y cuáles no, pues bajo la forma jurídica cooperativa, se han colado en los últimos tiempos realidades societarias, que seguro distan mucho de la visión que el constituyente tenía de las sociedades cooperativas que debían ser promovidas por parte de los poderes públicos.

Por ello, y recordando la inicial definición de identidad, como el conjunto de rasgos propios de un individuo o de una colectividad que los caracterizan frente a los demás y la conciencia que una persona tiene de ser ella misma y distinta a las demás, es conveniente precisar, para no titubear en la identificación de las cooperativas hoy en día, cuáles son esos rasgos característicos que las hacen diferenciarse del resto de sociedades mercantiles, y que por tanto les llevan a ser conscientes de su realidad diferenciada. Es aquí donde conviene resaltar que las sociedades cooperativas son sociedades mercantiles que aspiran al cumplimiento de unos valores como son los valores cooperativos, para lo que se dotan de principios de actuación que son los principios cooperativos, aspirando a la consecución de una serie de valores, que son los valores cooperativos.

Este doble plano valores-principios requiere de un deslinde conceptual ya realizado por míl2 y por la de tantos autores ${ }^{13}$, que en tantas

11 Hablamos del periodo o etapa constituyente iniciado en 1977 y que finalizó con la aprobación del texto constitucional actual.

12 Martínez Etxeberria, G. (2018, 19-23).

13 Atxabal Rada, A. (2016), Cracogna, D. (1991) (1994), Divar Garteiz-Aurrecoa, J. y Gadea Soler, E., (2002), Divar Garteiz-Aurrecoa, J. (2016), Fici, A. (2014), Gadea Soler, E. (2009), Lambert, P. (1970), Marcus, L. (1988), Martínez Charterina, A. (2016), Vaquero Sánchez, J. M, (2015). 
ocasiones no resulta sencillo, habida cuenta de la ubicación en ambos planos de realidades esenciales para la configuración de la identidad cooperativa, como puede ser la cooperación, la democracia, la solidaridad, la ayuda y tantas otras.

\section{Un breve análisis histórico de la evolución en la construcción de una identidad cooperativa reconocible}

Cuando hablamos de identidad cooperativa y siguiendo a la profesora GAMINDE EGIA ${ }^{14}$ es preciso advertir que "pretender definir el ADN cooperativo constituye una tarea muy compleja. Como ya hace tiempo señalaba el profesor CIURANA ${ }^{15}$, «intentar determinar la esencia de la cooperación no supone hallar una norma segura para resolver acerca de la ortodoxia de una cooperativa; pero sí supone encontrar los rasgos esenciales o ideas fundamentales que sirven para estructurar la misma».

Sin afán alguno de codificar y analizar toda la secuencia de ADN de estas cooperativas, sí que conviene recorrer brevemente el camino histórico hasta llegar al momento en el que nos encontramos, que no es otro que el de la existencia de un cooperativismo reconocido y reconocible, que convive con unas nuevas formas jurídico-societarias que encarnan un mal llamado cooperativismo, caracterizadas por ser opuestas a los valores y a los principios del verdadero cooperativismo y de los que brevemente daba cuenta previamente. No obstante, fijar unos mínimos elementos comunes que permitan establecer las bases para la identificación de estas sociedades cooperativas auténticas puede resultar algo más sencillo.

En esa tarea ha destacado históricamente la $\mathrm{ACl}$, que no es sino una asociación internacional que ya desde 1895 cuando se reúne por primera vez en Londres ha estado al servicio de las cooperativas, y entre cuyas funciones y no pocas veces a lo largo de la historia, está, ha estado y estará en el debate y la reflexión en torno a estas cuestiones identitarias así como en otras no tan centradas en la filosofía cooperativa, básicas en cualquier caso para la pervivencia del movimiento cooperativo tal y como lo hemos venido conociendo hasta nuestros días.

14 Gaminde Egia, E. y Martínez Etxeberria, G., (2019, 97-114).

15 Ciurana Fernández, J. M., (1965). 
En este sentido, no han sido pocas las asambleas mundiales de esta institución en la que las cuestiones en torno a los valores y los principios hayan sido el eje de las mismas, destacando sobremanera, la de Manchester (Reino Unido) de 1995, en la que el debate en torno a los valores, posibilitó una Declaración, la conocida como Declaración de Manchester ${ }^{16}$, en la que se fijaban una serie de mínimos en este ámbito. La Declaración de Manchester al fin y a la postre, posibilitó recoger en una declaración institucional, los valores cooperativos universalmente reconocidos, siendo éstos, los valores que habrían de ser válidos para la entrada de las cooperativas en el nuevo siglo. La citada Declaración de Manchester, incluía una nueva definición de cooperativa y recogía una importante revisión del sistema de principios cooperativos que había funcionado durante los últimos cien años, procediendo a deslindar conceptual y metodológicamente y de forma expresa la realidad de los valores y de los principios cooperativos. Así, la Declaración se iba a estructurar en dos partes diferenciadas pero complementarias entre sí.

De una, la primera y titulada «Declaración de la Alianza Cooperativa Internacional sobre la Identidad Cooperativa», en la cual se recoge la definición de cooperativa y una lista en la que quedan descritos ciertos valores cooperativos de referencia, los cuáles quedan clasificados y estructurados por un lado, los valores básicos «autoayuda, autorresponsabilidad, democracia, igualdad, equidad y solidaridad» y por otro, los valores éticos, tales como la «honestidad, transparencia, responsabilidad y vocación social».

En lo que a la definición y los principios cooperativos se refiere, queda establecido en la Declaración, que «los principios cooperativos son pautas mediante las cuales las cooperativas ponen en práctica sus valores», siendo éstos los siguientes: "adhesión voluntaria y abierta; gestión democrática por parte de los socios; participación económica de los socios; autonomía e independencia; educación, formación e información; cooperación entre cooperativas; e interés por la comunidad) ${ }^{17} \gg$.

De otra, la segunda parte y denominada «Informe sobre la Declaración de la Alianza Cooperativa Internacional sobre la Identidad Cooperativa», viene a clarificar el contenido de la primera parte.

16 Declaración de la ACl sobre la Identidad Cooperativa adoptada por la II Asamblea General de la Alianza Cooperativa Internacional en septiembre de 1995 en Manchester con motivo del Centenario de la Alianza Cooperativa Internacional.

17 Declaración de la Alianza Cooperativa Internacional sobre la Identidad Cooperativa, pp. 16-19. 
El mínimo común denominador de las cooperativas a lo largo y ancho del mundo y que viene a clarificar la referenciada Declaración, ya sean éstas cooperativas que desarrollan sus servicios y actividades en sociedades ricas o pobres, en oriente o en occidente, en el marco de regímenes capitalistas y comunistas, democráticos o no democráticos etc... lo constituye la identidad cooperativa, sobre cuya realidad trabaja y reflexiona la $\mathrm{ACl}$, quien finalmente traslada estos trabajos y reflexiones a Informes o Declaraciones como la antes analizada de Manchester de 1995, que establecen un marco cuasi-normativo respetado por la mayoría de las cooperativas en todo el mundo.

En cualquier caso, si queremos comenzar desde el inicio y en lo que a la construcción del ADN cooperativo se refiere, es preciso hacer mención a la Sociedad de Rochdale ${ }^{18}$ y a los principios de funcionamiento que establecían sus Estatutos de constitución, pues en estos estatutos se reglamentaron los que podíamos enumerar como los principios cooperativos, que fueron: la ayuda mutua, el control societario democrático, la gratuidad de los cargos, la libre adhesión y dimisión de los socios, la compraventa al contado, los intereses limitados al capital social y los retornos cooperativos. Si bien algunos de estos principios originales y originarios, como por ejemplo la compraventa al contado, hoy no encuentran sentido en nuestras sociedades actuales, no es menos cierto, que el resto de ellos, dos siglos después siguen estando vigentes y siguen siendo referentes de las cooperativas, lo que nos da pistas de la trascendencia de los mismos.

Cabe recordar que los principios originarios inicialmente recogidos en los Estatutos de la sociedad de Rochdale, han sido posteriormente revisados y actualizados por la $\mathrm{ACl}$ a lo largo de su historia y en las diferentes asambleas internacionales realizadas, siendo la $\mathrm{ACl}$ una de las más importantes referencias a la hora de fijar los elementos que han ido configurando lo que conocemos como la identidad cooperativa. No obstante, hoy en día la importancia que las cooperativas y la propia

18 En muchos manuales, artículos y estudios monográficos se reconoce a los pioneros de Rochdale como «realizadores del cooperativismo». Entre otros, Möller E. (1986, 23); Kaplan de Drimer, A. y Drimer B. (1981, 227); Mladenatz, G. (1969, 68); Uribe Garzón, C. $(2001,68)$. No obstante, también hay opiniones en otro sentido. Carrasco, por ejemplo, puntualiza que «habría que aclarar que no fue la de los Pioneros de Rochdale la primera experiencia asociativa habida en la historia y que su carácter pionero se refiere más que a la experiencia en sí, a la elaboración por parte de sus promotores de unos estatutos propios». Carrasco Carrasco, M. (1991, 2). En la misma línea Miranda señala que "el cooperativismo no nace en el año 1844: es el resultado de un proceso multisecular que se inicia en la cooperación primaria». Miranda, J. E. de $(2012,140)$. 
$\mathrm{ACl}$ otorga a los principios a la hora de fijar los elementos para establecer la identidad cooperativa, convive con la importancia, cada vez mayor, que tanto las cooperativas como la propia $\mathrm{ACl}$ concede a los valores cooperativos que las cooperativas aspiran a conseguir cumpliendo los principios de los que se dotan.

\section{Los peligros a los que se enfrenta el movimiento cooperativo desde el punto de vista de su identidad}

Las sociedades cooperativas desarrollan sus actividades y prestan sus servicios por todo el mundo, en el que conviven distintos marcos económicos. Así, en el mundo del s. XXI en el que nos encontramos, podemos encontrar una mayoría de estados cuyas economías, son economías de mercado, frente una minoría de estados (el desmoronamiento desde finales del s. $x x$ del bloque comunista, no ha hecho sino reducir considerablemente aquellos estados intervencionistas, pues la gran mayoría de éstos, pasaron rápidamente a adoptar rápidamente la economía de mercado como el marco de desarrollo de sus respectivas economías) en cuyas economías interviene y planifica el Estado con mayor o menor intensidad.

Los peligros que acechan a las cooperativas en estos tiempos, tienen similitudes y diferencias en tanto en cuanto se encuentren en un marco de desarrollo económico o en otro. No obstante, elementos como las crisis económicas o los condicionamientos a la autonomía de las cooperativas (por diferentes cuestiones que luego trataremos) son comunes a ambos marcos, como comunes son también los diferentes peligros a los que las cooperativas deben y deberán hacer frente.

\subsection{Los peligros a los que se enfrentan las cooperativas en los países con economías de mercado}

Las reiteradas crisis económicas que en el marco del desarrollo económico de la economía de mercado se han plantado ${ }^{19}$, se plantean y presumiblemente se plantearán, afectan a la totalidad de los operadores que compiten en un mercado cada vez más especializado, más

19 La crisis del petróleo en los inicios de los años 70, las más locales a nivel español y vasco de inicios de los años 80 y de los años 90, y finalmente y tras varios años de una situación de bonanza, la devastadora crisis financiera internacional iniciada en 2008 en USA y con posteriores ramificaciones a lo largo y ancho del mundo occidental. 
competitivo y más globalizado. Entre esos operadores económicos, se encuentran las cooperativas, las cuales, con sus defectos y virtudes, propias de su especial naturaleza, han de afrontar los embites de la economía y el mercado junto con el resto de operadores económicos con los que compiten.

Son en estos contextos de crisis donde mejor se pueden visualizar los peligros a los que las sociedades mercantiles capitalistas en general y las sociedades mercantiles cooperativas en particular pueden enfrentarse. Entre éstos, destacaré aquellos que afectan a lo más profundo de la identidad cooperativa, y que en demasiadas ocasiones quedan solapados a otros peligros también importantes como los aquellos que afectan al cortoplacista resultado económico del ejercicio u otros de similar naturaleza. Es en esa visión de los problemas que van más allá del corto plazo o del ejercicio económico concreto donde pondré el punto de mira a lo largo de este trabajo.

En los últimos 30 años, más concretamente desde que allá por 1989 cayese el telón de acero, la hegemonía de los países y las sociedades en las que el modelo capitalista es el modelo económico de referencia es indiscutible cualitativa y cuantitativamente, por lo menos en lo que se refiere a los estándares y variables macro y microeconómicas que manejan las grandes instituciones para evaluar la realidad socio-económico de los países ${ }^{20}$. Bien es cierto, que dentro de estas sociedades conviven diferentes realidades, con sus especificidades, sus colores y tonalidades, que abarcan todos los espectros, y que oscilan desde aquellos países radicalmente neoliberales en los que el Estado aparece como un observador de lo que acontece en el devenir del juego del mercado, hasta aquellos países en los que las reglas del mercado conviven con una mayor participación del Estado, que va más allá de la mera observancia, y que se muestra más o menos activa en cada caso a la hora de buscar ciertos equilibrios en pos de cierta justicia social que la economía de mercado por sí misma no es capaz de conseguir.

En cualquier caso, ya sean unos u otros, la percepción de que las sociedades en teoría más avanzadas desde el punto de vista del bienestar material y de la economía son cada vez sociedades más individualistas, es una constatación, pues no hay sino que ver la realidad que nos rodea en cuestiones como la gestión de las reiteradas y cíclicas crisis migratorias (valgan de ejemplo las crisis migratorias americanas y la del

20 Me refiero preferentemente, aunque no de forma exclusiva al Banco Mundial y al Fondo Monetario Internacional. 
Mediterráneo, al margen de otras igualmente trágicas y más silencias en nuestros entornos mediáticos más próximos), o tantas otras realidades más en las que se pone de manifiesto la crisis de valores en las que estas sociedades a mi juicio se ven sumergidas.

Valores como la solidaridad, la cooperación y tantos otros que han sido pilares sobre los que se han asentado la construcción de las sociedades más modernas y avanzadas, están cada vez más cuestionados, si bien no se puede obviar en este análisis aquellas personas y organizaciones que hacen de la defensa de estos valores su día a día. No obstante, la percepción de una visión de retroceso y de crisis de éstos valores, creo que es una percepción cada vez más peligrosamente generalizada.

Es precisamente en este contexto donde las cooperativas deben reivindicarse ${ }^{21}$, pues son sociedades en cuya identidad debe estar grabada la aspiración a la consecución de una serie de valores cooperativos como los comentados previamente de solidaridad y cooperación, al margen de otros más modernos que ya condicionan las agendas de éstas, como la protección del medio ambiente, la defensa ecológica del planeta etc...

Es en este contexto, donde las cooperativas deben posicionarse y más que nunca proyectarse como tal, para dar servicio y ofrecer productos a aquellas personas, ciudadanos, que puedan estar echando en falta el compromiso y el desarrollo de estos valores en otro tipo de sociedades mercantiles y en consecuencia, se decanten por los productos y servicios que puedan ofrecer las cooperativas, por ser plenamente conscientes que esto implica al margen de la calidad que el producto o el servicio pueda ofrecer, aspirar a la consecución de unos valores compartidos con la cooperativa, apoyando también una forma de hacer que comparte y respeta, y con la que de cierta forma pueda sentirse identificado.

Bien es cierto que las cooperativas no viven aisladas, sino que conviven con otras sociedades mercantiles capitalistas, cuyos fines igualmente legítimos como la obtención exclusiva del lucro o aspirar a un mejor posicionamiento en el mercado, son perseguidos con otras pautas de actuación o si se prefiere, con otros principios. Esta

21 Puede consultarse el Boletín de la Asociación Internacional de Derecho Cooperativa, en su número 36 del año 2002, en el que varios autores reflexionaron sobre este particular, valga de por ejemplo, Rosemburg, T. (2002, 15-25), Ispizua Zuazua, A. (2002, 25-37), Divar Garteizaurrecoa, J. y Gadea Soler, E., (2002, 37-45), Farías, C.A, (2002, 45-51), Del Burgo García, U., (2002, 51-121), Estarlich Martorell, V., (2002, 121-139. 
feroz competencia con otros operadores ha podido llevar a las cooperativas y en no pocas ocasiones a la fijación de objetivos cortoplacistas que han podido difuminar el verdadero fin social de la cooperativa 22 . No obstante, es preciso advertir que para lograr esos fines sociales y de forma previa, se ha de cumplir el primero de los objetivos de las cooperativas y de todas las sociedades mercantiles que como tal se precien, y que no es otro que el de la mera supervivencia, objetivo éste que en el contexto de crisis cíclicas vividas en los últimos tiempos ha sido en demasiadas ocasiones uno de los objetivos prioritarios sino el primero de los objetivos a cumplir por las cooperativas a lo largo y ancho del mundo.

La cuestión que trasciende a las actuaciones concretas de las cooperativas en busca de su supervivencia, no es otra que si estas cooperativas, habida cuenta de con quien compiten, en que marco, contexto y situación lo hacen, se alejan de estos valores, consciente o inconscientemente, pudiendo parecerse cada vez más a otras sociedades mercantiles capitalistas, y si además, ese distanciamiento o alejamiento de los valores cooperativos identificativos e identificadores de su realidad, es percibido o no por las sociedades en las que se desarrollan y ofrecen sus servicios y venden sus productos.

Este distanciamiento, al margen de los problemas de identidad a los que me referiré, también pueden generar una serie de problemas que van más allá de la propia cooperativa, pero que inciden en su posicionamiento en las sociedades y los mercados en los que están presentes, y en los que compiten precisamente por su idiosincrasia y vocación social y a modo de ejemplo, con unos tipos impositivos más beneficiosos respecto de otras sociedades de capital en impuestos como por ejemplo el Impuesto de sociedades.

Así en el caso, de España y más concretamente en el caso de Euskadi y en lo que se refiere a la regulación impositiva del impuesto de sociedades en el Territorio Histórico de Bizkaia23, reflexiones cómo las

22 Del Burgo García, U., op. cit, (2002. 51).

23 Los Territorios Históricos de Araba-Álava, Bizkaia y Gipuzkoa, conforme a la Ley de Concierto Económico vasco (Ley 12/1981, de 13 de mayo, del Concierto Económico con la Comunidad Autónoma del País Vasco, publicada en el $B O E, \mathrm{n} .{ }^{\circ} 127$, de 28 de mayo de 1981, Ley 12/2002, de 23 de mayo, por la que se aprueba el Concierto Económico con la Comunidad Autónoma del País Vasco publicada en el $B O E, \mathrm{n}$. ${ }^{\circ} 124$, de 24 de mayo de 2002), tienen y asumen el ejercicio de las competencias exclusivas que en materia normativa fiscal y tributaria en impuestos directos como el que estamos comentando del Impuesto de sociedades, que en el caso de Bizkaia queda regulado en la actualidad a través de la NF 11/2013, del Impuesto de Sociedades, de 5 de diciembre, publicada en el BOB n. ${ }^{\circ} 238$, de 13 de diciembre de 2013). 
realizadas por CEBEK (la asociación empresarial más representativa de las sociedades de capital del Territorio Histórico de Bizkaia) en mayo de $2017^{24}$ y que abogaban por reducir el tipo impositivo de las sociedades de capital hasta el mismo tipo impositivo que el de las sociedades cooperativas, es decir, una reducción de 8 puntos, desde el 28\% del tipo general hasta el $20 \%$ del tipo impositivo para las cooperativas, no hacen sino trasladar una realidad que hace mención al anhelo de las sociedades de capital de equiparase en el tratamiento fiscal de las sociedades cooperativas. Este histórico anhelo, reclamado de forma cíclica por algunas asociaciones como la comentada, reflejan en mi opinión un sentir que me lleva a plantearme la siguiente cuestión: ¿por qué se ha planteado históricamente y se ha de plantear una fiscalidad diferente para el caso de las sociedades cooperativas y el resto de sociedades de capital?

La respuesta resulta sencilla desde un punto de vista teórico ${ }^{25}$, pues es precisamente la especial naturaleza e idiosincrasia de las cooperativas, que hunden sus raíces en las finalidades sociales que persiguen, la que hace que la colectividad, a través de sus representantes e instituciones, establezcan normas como las que acabo de ejemplificar, en este caso de carácter fiscal y tributario, que hacen a las cooperativas acreedoras de un trato fiscal beneficioso respecto de otras formas jurídicas societarias, por entroncar con valores que deben hacer uno con el interés general.

El problema más que desde el punto de vista teórico, se plantea, en el caso de que las cooperativas se alejen de esta forma de proceder y de orientar sus finalidades sociales, en definitiva, en el caso de que las cooperativas se desnaturalizasen ${ }^{26}$, y consecuentemente se equiparasen a otro tipo de sociedades que no son acreedoras de este trato, y por ende careciese de sentido cualquier protección o beneficio por parte de la comunidad hacia éstas. Por esta y por otras cuestiones que afectan directamente a su forma de ser como sociedades cooperativas deben profundizar y asentar su naturaleza cooperativa.

Al margen del previamente analizado tratamiento fiscal en el impuesto de sociedades del que se pueden beneficiar las cooperativas,

24 Fuente Diario Deia de 10 de mayo de 2017. «El presidente de los empresarios vizcaínos aboga por que esta reforma fiscal, que debe ser «sosegada y coordinada» entre las tres haciendas forales, incluya también cambios para rebajar la presión fiscal de las empresas comunes hasta la que tienen las cooperativas».

25 Sobre esta materia ha trabajado en profundidad Atxabal Rada, quien ha publicado destacados artículos entre los cuales se encuentran Atxabal Rada, A., (2018, 137166); y (2016, pp. 285-307).

26 Del Burgo García, U., op. cit, $(2002,51)$. 
amén de otros tributos, es preciso advertir, que en el hipotético caso de posibles desnaturalizaciones de su identidad, cabe pensar en la posibilidad real de que este tratamiento fiscal y tributario singular pueda correr peligro en un futuro más o menos lejano, pudiendo consecuentemente y en el caso de que se produjese, poner en peligro el equilibrio económico de las cooperativas.

Al margen de estas potenciales afecciones en su tributación que pudiesen plantearse a futuro ante la desnaturalización de la identidad cooperativa, existen otros peligros que se ciernen sobre las cooperativas y su identidad que también constituyen un peligro. Me estoy refiriendo a la apropiación de alguno de sus elementos definitorios más reconocidos, por parte de terceros interesados, quienes, sin ser verdaderas cooperativas, es decir, siendo "falsas cooperativas», actúen como auténticas cooperativas o bajo la proyección pública de que lo son, pudiendo llegar a confundir a la ciudadanía de las sociedades en las que se desarrollan, ofrecen sus servicios y venden sus productos.

En este sentido cabe señalar que estas falsas cooperativas no hacen sino fraude de ley con el fin de obtener las condiciones más favorables de las que se pueden beneficiar las verdaderas cooperativas, tales como las ya comentadas ventajas fiscales y tributarias o algunos aspectos regulatorios de las relaciones laborales de sus miembros ${ }^{27}$. No obstante, es preciso distinguir en la práctica la existencia dos fenómenos antagónicos como el de las hasta ahora comentadas las «falsas cooperativas», entendidas estas como sociedades con forma jurídica de cooperativa que, sin embargo, se apartan de sus rasgos configuradores y definitorios como cooperativas, y las «cooperativas de hecho, pero no de Derecho», entidades que cumplen voluntariamente con los principios cooperativos, pero por diferentes razones (régimen legal, fiscalidad...) han preferido constituirse en otro tipo legal.

Respecto de los problemas referidos a su identidad como cooperativas, son las primeras las verdaderamente peligrosas para las auténticas cooperativas que cumplen con los valores y principios cooperativos

27 Esta cuestión ya fue planteada y observada por Orozco Vilches, J. hace ya más de veinte años, cuando afirmaba que «la auténtica cooperativa se propone servir adecuadamente a las necesidades de sus socios (económicos o no), en armonía y supeditadas a la sociedad entera. Constituyen un magnífico ejemplo de ayuda mutua y no debe hallarse dominada ni por la idea de grupo ni por el egoísmo de sus componentes: en ella predominará la idea de servicio y desinterés, y estos servirá para diferenciarlas de todas las falsas cooperativas organizadas en plan de negocio». Orozco Vílchez, J. (1997,59). 
y con las leyes reguladoras de su realidad, y los son por varios motivos entre los que a mi juicio sobresalen los siguientes:

El primero de ellos hace mención a la confusión que pueden generar entre la ciudadanía a la que ofertan sus productos y servicios, y que en muchas ocasiones puedan acercarse a la "falsa cooperativa» creyendo de manera equivocada que es una cooperativa con unos valores cooperativos a cuyo cumplimiento aspira y unos principios cooperativos que son sus pautas de actuación y sus elementos distintivos respecto de la forma de operar de otras sociedades mercantiles.

En segundo lugar, destacaría aquellas cuestiones que tienen que ver con el desvío etimológico y el "merchandaising» comercial que las «falsas cooperativas» utilizan deslealmente respecto de realidades esenciales para proyectar lo que el verdadero cooperativismo significa. Realidades como cooperativo o colaborativo, enmarcadas en un contexto de economía cooperativa o colaborativa ${ }^{28}$, reclaman mi atención por importantes razones.

Entre estas razones resulta muy llamativa el desvío intencionado entre la realidad de las cosas y la proyección de las mismas que estas mercantiles realizan. Así por ejemplo cuando hablamos de la economía colaborativa, ésta, en esencia puede evocar al altruismo, la mutua ayuda en la búsqueda de una finalidad común etc..., lo que no ocurre en la realidad de plataformas autodenominadas de economía colaborativa del transporte como Uber o Blablacar, en la que éstas plataformas intermediarias de servicios (con sus diferencias en cuestiones organizativas, de servicio etc...) logran pingues beneficios por la intermediación entre usuarios con distintos intereses y con uno común a todos ellos, minimizar el costo de un servicio conforme a los patrones tradicionales de la prestación de servicios para el transporte de pasajeros ${ }^{29}$. Para evitar esos desvíos intencionados y siguiendo a ARRIETA IDIAKEZ ${ }^{30}$, resulta necesaria la colaboración público-privada en el fomento de la economía colaborativa con el fin último de ser una alternativa a la economía informal de la que en su opinión trae causa de la falsa economía colaborativa.

28 Economía colaborativa concepto que en lo que a su calificativo proviene etimológicamente de colaborar lo que significa atendiendo a la primera acepción que la propia RAE recoge en su diccionario: "Trabajar conjuntamente con otras personas en una tarea común, normalmente en obras de creación, y en especial cuando se hace como ayuda o de forma desinteresada».

29 Resulta interesante en mi opinión y respecto al establecimiento de una postura crítica con el concepto de economía colaborativa, el libro de Slee, T. (2016).

30 Arrieta Idiakez, F. J, $(2019,23)$. 
Más allá del estudio de las múltiples ramificaciones y afecciones jurídicas que este tipo de realidades implica y sobre las que no es mi objetivo profundizar en el presente trabajo, lo que es una constatación es el desvío intencionado entre lo que es en realidad colaborar y lo que estas sociedades mercantiles realizan, lo que en mi opinión se ha convertido en un importante "merchandaising» comercial de este tipo de plataformas, que permite construir artificialmente una imagen que tantos años y esfuerzo ha tardado en conseguir el cooperativismo proyectando sus valores y principios de actuación. Por ello, el cooperativismo como movimiento, debe estar vigilante debiendo contrarrestar es «merchandaising» comercial reforzando su compromiso con los valores y principios, pero también proyectándolos hacia afuera.

\subsection{Los peligros a los que se enfrentan las cooperativas en los países con economía intervencionistas}

En los países del mundo en los que la intervención del estado en las cuestiones económicas es total o cuando menos muy amplia, el problema de fondo que condiciona los elementos definitorios de la identidad cooperativa por encima de los demás, es la falta de autonomía de las cooperativas en el desarrollo de sus operaciones en busca del cumplimiento de sus fines societarios, manifestándose esa falta de autonomía y en muchos de los casos desde el momento mismo del nacimiento de la cooperativa.

Siguiendo a modo de ejemplo el caso de la República de Cuba31 y los planteamientos socialistas sobre la que asienta su desarrollo, las cooperativas de trabajo se erigen en una alternativa de los trabajadores al sistema capitalista. En este sentido autores referencia del pensamiento conocido socialismo utópico como FOURIER SAINT-SIMON u OWEN ${ }^{32}$ ya identificaron en su momento y de forma teórica que la realidad de cooperación y la idea de socialismo que defendían, podrían estar emparentadas.

En la actualidad y como recogía previamente, la $\mathrm{ACl}$ como la asociación que identifica los principios del cooperativismo a nivel mundial y establece las aspiraciones cooperativas en clave de valores, fija cuales

31 Por ser uno de los pocos países que mantiene una intervención férrea de la economía por parte de los poderes públicos, a pesar de las últimas tibias aperturas que afectan a los llamados cuentapropistas.

32 Lichtheim, G., (1975). 
han de ser las cualidades de las cooperativas, estableciendo las diferencias con las sociedades genuinamente capitalistas, a pesar de lo cual, resulta preciso advertir que "cada cooperativa constituye una realidad concreta y determinada, sujeta a condicionantes de tipo cultural, económico, histórico, político y social, que las particularizan de análogas sociedades de igual naturaleza jurídica ${ }^{33}$ ».

En el caso que vamos a tratar en este trabajo y que ejemplifica los problemas a los que se pueden enfrentar las cooperativas en los países cuyos poderes públicos intervienen en la planificación de la economía, es por conocido, el caso de Cuba. En este caso, los principios y valores cooperativos recogidas recurrentemente por la $\mathrm{ACl}$ en sus Declaraciones, concuerdan cuando menos desde el punto de vista teórico (la práctica es otra cuestión, si cabe más compleja) con algunos de valores y principios que inspiran la propia Constitución cubana.

Siguiendo ya no sólo la Constitución cubana, sino su desarrollo normativo, y haciendo mías las conclusiones a las que llega PUYO ARLUCIAGA ${ }^{34}$ tras analizar el Decreto-Ley cubano 305/201235, de las cooperativas no agropecuarias, y más concretamente su artículo cuarto, podemos afirmar que realidades como la «voluntariedad, cooperación y ayuda mutua, decisión colectiva e igualdad de derechos de los socios, autonomía y sustentabilidad económica, disciplina cooperativista, responsabilidad social, contribución al desarrollo planificado de la economía y al bienestar de sus socios y familiares, se aproximan bastante a los siete principios enunciados por la $\mathrm{ACl}$ en su congreso de Manchester en 1995».

No obstante, esta identificación formal se ve alejada en la aplicación práctica de los mismos, pues en el caso cubano, la interpretación «sui generis» de estos principios y valores resulta a mi parecer destacable, pues es una interpretación que merma en la mayoría de los casos la autonomía de las cooperativas, aproximándolas en su praxis más a empresas de carácter estatal que a cooperativas homologables a las que conocemos en los países occidentales.

La actualización de la interpretación de la Constitución cubana extendiendo la inicialmente constitucionalizada realidad de las

33 Martínez Etxeberria, G. y Mata Diestro, H., (2018).

34 Puyo Arluciaga, A.M., 2014, (180-181).

35 Decreto-Ley 305 del Consejo de Estado (CE): «De las Cooperativas no Agropecuarias». Gaceta Oficial de la República de Cuba No. 053 Extraordinaria de 11 de diciembre de 2012, La Habana. 
cooperativa agropecuaria al resto de las cooperativas ${ }^{36}$ y motivada precisamente por el surgimiento de cooperativas en otros sectores económicos y ante las cíclicas crisis sistémicas de su economía, ha puesto de manifiesto ante el desarrollo de éstas, que la cooperativa puede ser un modelo que «encaje» también en estos sistemas, siempre y cuando el Estado garantice su autonomía y no estrangule las mimas.

\section{La educación y la formación cooperativa: una realidad necesaria en la consolidación de una identidad cooperativa para el s. XXI}

Independientemente de la subsunción de la educación en la categoría de los principios cooperativos, más concretamente siendo el quinto principio cooperativo y al margen de las discusiones doctrinales en las que se plantea si también la educación puede considerarse un valor cooperativo al que las cooperativas deban aspirar, lo que resulta evidente es la necesidad en muchos casos y contextos, de una formación adecuada de los miembros que integran las sociedades cooperativas y también de quienes se relacionan con ellas en muchos y cada vez más ámbitos que afectan a su día a día.

Esta educación y formación cooperativa ha de estar orientada y dirigida preferentemente que no exclusivamente ${ }^{37}$ a la totalidad de los miembros que integran la comunidad cooperativa, y resulta si cabe más necesaria en el caso de las personas que aspiran a integrarse en una sociedad cooperativa por primera vez, independientemente del sector estratégico en el que éstas desarrollen sus actividades y ofrezcan sus servicios y no sólo desde un punto de vista de la cualificación técnica exigible, sino desde la exigencia cada vez más necesaria de una cualificación en valores cooperativos de las personas que aspiren a completar las estructuras de las sociedades cooperativas modernas del S. XXI, pues son ellas quienes encarnan el modelo y por ende son las llamadas preferentemente a defenderlo frente a los peligros que se ciernen sobre ellas, independientemente se encuentren en un escenario socioeconómico de economía de mercado o intervencionista por parte del Estado.

36 Sobre estas cuestiones resultan de interés las aportaciones de Fernández Peiso, A. (2012); Donéstevez Sánchez, G. $(2016,60)$.

37 Resulta de interés, en el análisis de la proyección de la cultura cooperativa en la educación general la obra de Inglada, M. E., Sastre Centeno., J. M. y Villaroya Lequericaonaindia, M. B, (2015, 122-147). 
Es por ello, que el ámbito educativo y formativo cooperativo debe erigirse en un pilar sobre el que se asienten las cooperativas de presente y de futuro. Por ello, resulta necesaria una formación integral del cooperativista, sobre todo aquellos cooperativistas jóvenes que abarque ámbitos educativos y formativos diferentes y complementarios ${ }^{38}$, como son el ámbito de la formación específica en valores y principios cooperativos, el ámbito propio de los condicionantes de gestión de las cooperativas y el de la formación técnica y específica atendiendo al sector estratégico y la actividad a la que se dedique la cooperativa.

Para todo ello, las cooperativas tienen una herramienta específica de su forma jurídica que es el fondo de educación y promoción ${ }^{39}$, fondo que, siguiendo a MARTíN CASTRO ${ }^{40}$, «es un instrumento orientado a garantizar la efectiva aplicación de los principios cooperativos, puesto que es el elemento de financiación reservado por disposición legal, que resulta inembargable, irrepartible e indisponible, para el desarrollo de los compromisos que conllevan los enunciados de los principios»

\subsection{La formación en valores cooperativos}

La forma en que las cooperativas compiten en el mercado globalizado es, efectivamente, una forma singular, con muchos años de historia, que les ha permitido posicionarse de una manera distinta en ese mercado, si bien la cada vez mayor competencia y los cada vez más complejos retos a los que se enfrentan todas las sociedades mercantiles en general y las cooperativas en particular, obliga a éstas a incorporar y crear nuevas «formas de hacer» y ampliar y expandir sus áreas de negocio posibilitando la aparición un riesgo, como es el de poder perder sus rasgos de identidad original, en definitiva su desnaturalización como cooperativa.

A fin de evitarlo, resulta a mi juicio trascendental reforzar la identidad cooperativa de sus miembros (y más en aquellos entornos, situacio-

38 Como los que posibilita la formación dual, tipo de formación impulsado por las nuevas políticas educativas (ejemplo de eficacia en la inserción al mundo laboral de los jóvenes en Euskadi), sobre las que profundizan los autores Prieto Padín, P. (2016, 237268) y Arrieta Idiakez, F.J. (2018, 75-96).

39 En opinión de PASTOR SEMPERE, el fondo de reserva de educación y promoción cooperativa, "es un elemento realmente específico de la sociedad cooperativa, hasta el punto de que constituye uno de sus rasgos tipológicos sobresalientes». Pastor Sempere, C. $(2001,81-127)$.

40 Martín Castro, M.P., en la obra colectiva Vázquez Ruano, T (Coord.) (2013, 643655). También puede consultarse Macías Ruano, A.J., (2017). 
nes y casos, en los que la transmisión de estos valores y el conocimiento de los principios no se haya podido transmitir de la forma natural, es decir, a través de la familia o el entorno cooperativo más próximo), a través de la formación en principios y valores, garantizando así que los nuevos profesionales (ya sean éstos socios cooperativos o trabajadores que desempeñen sus funciones en las cooperativas) que se incorporen al mundo cooperativo conozcan la idiosincrasia cooperativa, base de la diferenciación frente a otros modelos societarios y la clave del mayor o menor éxito que pueda alcanzar como organización cooperativa.

En definitiva, la formación en valores cooperativos debe ser uno de los elementos básicos en la cualificación profesional de los miembros a integrar por las cooperativas y un elemento importante a considerar en las personas y mercantiles que se relacionen con la cooperativa a la hora de desarrollar sus fines sociales.

Al margen de la formación específica en valores y principios orientada a los miembros que integran la cooperativa, la educación cooperativa en valores y principios cooperativos como realidad más amplia y expansiva, debe desarrollarse más allá de la propia cooperativa, incidiendo especialmente en el área en el que su nivel de influencia sea importante o esté llamado a serlo, siendo el fin último de todo ello el trasladar la filosofía del cooperativismo y sus pautas de funcionamiento no sólo a sus miembros sino al de la ciudadanía receptora de sus servicios y consumidora de sus productos.

Por ello, las claves educativas en el traslado de los valores y principios cooperativos, habrán de adecuarse a la evolución del cooperativismo en dichas áreas y contextos, posibilitando un mayor conocimiento de las cooperativas y su realidad distintiva respecto de otras realidades societarias, lo que en ciertos casos en los que haya una identificación con sus valores y principios, pueda llevar a estos ciudadanos a «apostar» por las cooperativas en detrimento de otras opciones.

Sólo a través de la educación y formación cooperativa, se podrá conseguir que la sociedad en general ${ }^{41}$, y los jóvenes en especial como

${ }^{41}$ La importancia de la educación y la formación en la transmisión de los valores y principios sobre los que se asientan las cooperativas, no sólo depende de ellas mismas, sino que el contexto en el que desarrollan y su ámbito educativo resulta decisivo en la posibilidad de implantación de las distintas políticas educativas. En este sentido, y habida cuenta de la importancia que tiene el movimiento cooperativo en Euskadi y cuya realidad se ha trasladado en este trabajo en varias ocasiones y a modo de ejemplo, resulta destacable en este ámbito, es decir, en el de la Comunidad Autónoma de Euskadi, el funcionamiento de su actual modelo institucional y territorial, modelo que ha ayudado de forma clara en el desarrollo humano y social del País, en particular si se tienen en cuenta los datos relativos al IDH (Índice de Desarrollo Humano), que mide el desarrollo de un país 
gestores del futuro ${ }^{42}$, conozcan las bondades del sistema cooperativo y su potencial para erigirse en un agente transformador más del entorno en el que se ubican y en el que se desarrollan.

En esa educación y formación cooperativa, al margen de conocer las esencias del cooperativismo, habrán de estar presentes también nuevos valores que las cooperativas deben hacer suyos si aspiran a ser una «vanguardia» a nivel global. Entre estos valores de nuevo cuño no deben faltar el conocimiento de lo que es y significa el trabajo digno y de calidad ${ }^{43}$ y la potenciación en sus estructuras corporativas de este tipo de trabajo, con el fin último de erigirse en sociedades mercantiles creadoras de un tipo empleo, caracterizado por la protección de sus socios y trabajadores en lo que se refiere a cuestiones como el desarrollo personal y profesional del trabajador, la conciliación personal y familiar, amén de otros condicionantes laborales más, siendo uno de los principales retos al que se enfrentan las cooperativas actualmente, pues deben ser vanguardia en estas cuestiones además de competir en un mercado globalizado cada vez más exigente en ámbitos como la calidad del servicio, el coste del producto o servicio ofertado, etc...

También debe ser referencia para el cooperativismo y sus políticas societarias la proyección y formación sobre nuevos valores sociales y por ende nuevos valores cooperativos como el respeto al medio ambiente, el desarrollo sostenible en su producción y sus políticas de crecimiento y expansión, y la potenciación de los valores del ecologismo.

en función de tres dimensiones: salud, educación y nivel económico, que vaya por delante son realidades trascendentales para cualquier sociedad avanzada pero también para las cooperativas en el cumplimiento de sus objetivos sociales. Respecto de la importancia del modelo institucional y territorial vasco en el desarrollo humano y social y humano de Euskadi ha profundizado Larrazabal Basañez, S., (2018, 328).

42 El profesor Martínez Etxeberria, G. habla de la juventud como valor cooperativo en las sociedades mercantiles cooperativas del siglo XXI (Martínez Etxeberria, G. 2014, 68). En dicho capítulo resalta el valor de juventud y el valor de los jóvenes como presente y futuro del movimiento cooperativo. Sobre estas cuestiones, profundiza Arrieta Idiakez, F.J., 2017, (123-154).

43 Arrieta Idiakez, J., López Rodríguez, J. y Martínez Etxeberria, G., «¿En qué medida las cooperativas, como entidades de la economía social, ofrecen una protección social adecuada a sus socios?», ponencia defendida en el marco del Congreso conmemorativo del centenario de la OIT, celebrado en Sevilla en el mes de febrero de 2019. El artículo científico presentado para su publicación ante el Comité científico ha sido aceptado y su publicación está pendiente. López Rodríguez, J., (2019, 115-129). 


\subsection{La formación específica relacionada con la gestión de la cooperativa atendiendo a su especial naturaleza}

Las cooperativas de igual manera que otras sociedades mercantiles en el desempeño de sus funciones societarias, desarrollan actuaciones concretas en diferentes ámbitos como la gestión empresarial, las responsabilidades de sus gestores, el liderazgo, las relaciones laborales etc... En el caso de las cooperativas y teniendo en cuenta su especial naturaleza, la formación en estas áreas se torna si cabe más necesaria, pues los condicionantes en la toma de decisiones se multiplican frente a otros formatos societarios, debido a su finalidad social, su funcionamiento democrático y por la cualificación del socio-cooperativista. Para ello, y como comentaba previamente, la cooperativa cuenta con una herramienta financiera y normativa como es el fondo de educación y promoción.

La especial idiosincrasia de la cooperativa, así como la democracia reflejada en la participación de sus socios en la gestión de la cooperativa a través de sus órganos legal y estatutariamente establecidos, también requiere en muchas ocasiones y en los tiempos que corren de políticas formativas específicas que han de completar la previamente trabajada educación y formación en valores.

En este sentido, al margen de las tradicionales formaciones específicas para el afianzamiento de la gestión de la cooperativa que puedan afectar a cuestiones más tradicionales como el liderazgo, las relaciones societarias etc... se plantean como necesarias otras más novedosas políticas formativas que precisamente tiendan a mejorar gestión de la cooperativa a la par que profundicen en su democratización, mejorando el canal de comunicación e información a los socios y a los trabajadores, como paso y elemento previo al fomento de su participación en la vida de la cooperativa más allá de las obligaciones específicas que tengan sean éstas de tipo laboral o de otro tipo.

Para ello, al margen de un conocimiento mayor de la realidad societaria cooperativa a nivel normativo y estatutario, que fácilmente puede obtenerse a través de una mínima formación en aspectos jurídico-societarios, resulta más necesaria si cabe una formación específica en TICs como una herramienta novedosa, no sólo ya desde el punto de vista de la mejora técnica y profesional del socio y el trabajador (de la que daré cuenta en el próximo epígrafe), sino desde el punto de vista de la profundización en la participación democrática de los socios en las cuestiones que afectan a la propia cooperativa, posibilitando una mejor canalización de la comunicación entre los socios cooperativistas, mayor y más rápida comunicación de la información que afecta a la 
cooperativa, lo que favorezca una mayor transparencia de la misma y por tanto pueda reflejar un mayor sentimiento de participación y adhesión de sus socios para con la cooperativa.

En conclusión, avanzar hacia un nuevo modelo de gestión de la cooperativa que seguro aporte, la oportunidad para los más jóvenes de iniciar una vida profesional en un entorno diferente con el que se sienten identificados, no sólo ya desde el punto de vista de la aspiración a la consecución de unos valores como los de solidaridad, democracia y responsabilidad, a los que la cooperativa aspira y son hoy más necesarios que nunca, sino desde el punto de vista de sus formas de gestión, en el que la participación democrática en la misma les haga partícipes activos en la toma de decisiones, siendo y sintiéndose por tanto responsables de un proyecto compartido.

En esas sensaciones y como foco de atracción para los más jóvenes, el uso de las herramientas TIC puede ser de destacable ayuda, erigiéndose en el canal principal que no el único elegido para llevar a cabo tal fin como es el de informar y la comunicar, como paso previo a participar cono conocimiento y responsabilidad.

\subsection{La formación técnica específica en las cooperativas atendiendo a sus necesidades productivas ${ }^{44}$}

En primer lugar y de forma previa, entenderemos por formación técnica y para este trabajo de investigación, aquella que tiene relación directa con aspectos y realidades esenciales para el desarrollo de actividades que tengan relación con la actividad de la cooperativa, ya sea ésta a nivel productivo, administrativo, o comercial.

Respecto de la impartición de este tipo de formación en el ámbito de Euskadi y conforme al proyecto de investigación referenciado, resulta importante destacar que las cooperativas se apoyan en centros educativos y formativos de su entorno más próximo y también suelen acudir en función de las necesidades específicas que circunstancial-

44 Las conclusiones que se trasladan a este artículo traen causa del proyecto de investigación conocido como Trebatzen II, del que el grupo de investigación «Cooperativismo, Fiscalidad, Fomento, Relaciones Laborales y Protección Social» de la Facultad de Derecho de la Universidad de Deusto al que pertenezco junto con otras universidades como la UPV/EHU y la Mondragoneko Unibertsitatea, participa. Resolución del Directo de Economía Social por la que se resuelve el expediente de petición de ayuda al amparo de la Orden de 29 de agosto de 2018, de la Consejera de Trabajo y Justicia, por la que se convocan y regulan las ayudas para la Formación de la Economía Social, publicada en el BOPV n. ${ }^{\circ}$ 173, de 7 de septiembre de 2018. 
mente puedan tener a formadores específicos (consultores) para trabajar determinados temas o, a los proveedores, para la formación sobre aspectos técnicos que inciden en su actividad, o incluso apoyarse en otras asociaciones supra-cooperativa en las que las cooperativas participen la Federación de cooperativas.

En lo que respecta a la financiación de la educación y la formación por parte de las cooperativas, en muchos de los casos, la misma es subvencionada por las Administraciones Públicas a través de subvenciones y otros mecanismos normativamente previstos, y en otras ocasiones es la propia cooperativa la que financia la misma a través de los mecanismos corporativos establecidos a tales efectos como el previamente reflejado fondo de educación y promoción.

Este tipo de formación suele responder a las necesidades concretas del sector, de los puestos de trabajo o de los proyectos en los que la cooperativa esté o pueda verse inmersa en un plazo temporal próximo, pudiendo venir delimitada por los proyectos y por los planes de gestión, en los cuales se detectan necesidades muy específicas. En este sentido resulta preciso destacar, los planes de formación que las cooperativas establecen periódicamente en busca de una serie de objetivos prioritarios para la cooperativa, orientando la formación a materias en relación directa con la gestión de la cooperativa ya trabajada en el epígrafe anterior, como el liderazgo, el desarrollo de equipos y personas, u otras más específicas atendiendo a las necesidades de los distintos departamentos que conforman la estructura empresarial cooperativa como puedan ser materias como la prevención de riesgos laborales, los idiomas, las nuevas tecnologías de la comunicación y la información desde su perspectiva más técnica y en relación con su manejo y uso, amén de otras relacionadas directamente con las necesidades productivas concretas de cada cooperativa.

Finalmente, cabe indicar que las necesidades formativas de los socios y trabajadores de las cooperativas quedan reflejadas en los planes de formación que las cooperativas fijan temporal y periódicamente, y éstos, no difieren mucho de cualesquiera otros planes formativos que establezcan otras formas jurídicas para la formación de sus trabajadores, pues para las cooperativas así como para el resto de las formas jurídicas empresariales, la formación continua de los trabajadores y sus cuadros directivos es a día de hoy un elemento esencial para su supervivencia ante los cada vez más rápidos cambios en todas las áreas posibles que afectan a su ámbito de negocio y desarrollo. 


\section{Conclusiones}

PRIMERA: Las sucesivas y periódicas crisis económicas que han sufrido a lo largo de la historia las economías y las sociedades han impulsado en innumerables ocasiones una forma de emprender y gestionar que en momentos de bonanza suele ser menos habitual, la cooperativa, con su especial naturaleza e idiosincrasia.

Desde sus orígenes allá por 1844 con la puesta en marcha de la experiencia de Rochdale y desde 1895 a través del espacio de reflexión que ha posibilitado y posibilita la Alianza Cooperativa Internacional, la cooperativa primero y el cooperativismo después, se han guiado en el cumplimiento de sus objetivos sociales por unos principios, los principios cooperativos, que constituyen la base filosófica del movimiento cooperativo, como son: la adhesión voluntaria y abierta; gestión democrática; participación económica de los miembros; autonomía e independencia; educación, formación e información; cooperación entre cooperativas y preocupación por la comunidad. Estos principios han sido recogidos de forma expresa en diferentes formatos como la Declaración sobre la Identidad Cooperativa de Manchester de 1995, los diferentes textos legislativos a nivel estatal y los estatutos corporativos de las cooperativas que operan a lo largo del mundo, lo que ha posibilitado un importante grado de asunción de los mismos por parte de los cooperativistas y otros operadores que han desarrollado diferentes funciones en torno a las cooperativas.

Desde sus más remotos orígenes los principios cooperativos han ido evolucionando y adaptándose a las nuevas circunstancias de la mano de la Alianza Cooperativa Internacional, como han ido evolucionando los valores a cuyo cumplimiento aspiran las cooperativas. Sin embargo, hoy en el marco de un mundo globalizado e interconectado como el que vivimos, en el que la revolución digital es una constatación que está cambiando la forma en la que las personas nos hemos relacionado en los últimos siglos y en el que una crisis de valores de los valores cooperativos más tradicionales como la cooperación o la solidaridad asola las sociedades en teoría económicamente más avanzadas, y más que nunca, han de trabajarse y proyectarse hacia el futuro los valores cooperativos como la cooperación, la solidaridad y la democracia, amén de otros nuevos valores en los que la cooperativa deber erigirse en ejemplo en su seguimiento como la sostenibilidad, la protección del medio ambiente o el desarrollo de políticas laborales en pos de un trabajo digno y de calidad, para intentar alcanzar una salida fiable y lo más duradera posible al permanente contexto de crisis. 
SEGUNDA: En esa labor, es decir, en la labor de transmitir y proyectar dichos valores, la educación y formación no sólo de carácter técnico y profesional, sino también la formación al nivel de los valores cooperativos dirigida a los dirigentes, trabajadores y socios de las empresas cooperativas y a quienes con ellos se puedan relacionar en distintos niveles, ha de ser la herramienta empleada, pues se ha producido un cambio en el paradigma de la transmisión de los valores y los principios cooperativos, cuando menos en las sociedades más económicamente avanzadas, pues los nuevos cooperativistas, a diferencia de aquellos que por su realidad vital no recibieron o no requirieron de una política educativa y formativa corporativa en esta materia para conocer y asumir la realidad de los planteamientos cooperativos, necesitan en muchos casos y para conocer la tradición cooperativa ser educados y formados en dicha dirección. Precisamente, y por ese cambio de paradigma, lo que antaño hubiese sido impensable, es decir, formar en valores a los cooperativistas y su entorno, se muestra hoy una necesidad que ha de completarse como en cualquier otra forma jurídica empresarial con la formación técnica y profesional y la formación de gestión, en pos de mejorar la realidad empresarial de la propia cooperativa.

Por ello, y al margen de la formación en el ámbito más interno de la cooperativa, resulta necesaria de la misma manera, una labor educativa cooperativa más amplia enfocada no sólo a la propia cooperativa y a quienes de forma más o menos directa se relacionan con ella, sino al el resto de las sociedades en las que las cooperativas desarrollan sus actividades, pues el riesgo de desnaturalización del cooperativismo y de su percepción como realidad mercantil específica sobrevuela la realidad de no pocas cooperativas sobre todo en los estados más avanzados económicamente.

TERCERA: El reforzamiento educativo y formativo del movimiento cooperativo y su entorno es más necesario que nunca, pues acechan al movimiento en un contexto globalizado y de mayor competencia empresarial, de surgimiento de cada vez más nuevos y originales productos y servicios, de cada vez más novedosos condicionamientos económicos a nivel macro y microeconómico, de nuevas y cada vez más complejas relaciones socio-laborales etc... una serie de peligros como la intención de beneficiarse del modelo por parte de terceros que ni son ni asumen los verdaderos postulados del cooperativismo (las «falsas cooperativas») o la intención de otras formas jurídicas de equipar a las cooperativas con sus formas jurídicas en pos de obtener un tratamiento fiscal y tributario lo más análogo posible. En este contexto, la 
exigencia de cada vez más y mayor flexibilidad, mayor creatividad e innovación en términos de creación de valor, no deben afectar a la verdadera esencia de las cooperativas, que son los principios y valores que constituyen su ADN, sino que deben plantearse como retos e incentivos para la mejora continua de las cooperativas y para la consolidación del modelo cooperativo a nivel global.

CUARTA: Para hacer frente a esos peligros como el referido de las «falsas cooperativas», el cooperativismo debe erigirse en el mayor valedor de su realidad y acompañar a los poderes públicos en la labor de identificación de las sociedades cooperativas que como se establece constitucionalmente en España, han de ser fomentadas por ellos. En este sentido, la elaboración de rankings con criterios objetivos que permitan identificar "verdaderas cooperativas» puede ser un instrumente aceptable a fin de evitar el intrusismo de otras formas jurídicas que sólo pretendan el beneficio que les confiera la forma jurídica cooperativa y no los deberes y responsabilidades que la forma jurídica cooperativa comporta.

ÚLTIMA: El cooperativismo y para posibilitar su supervivencia en los términos en los que se ha venido desarrollando a la lo largo de la historia y hasta nuestros días, debe erigirse en vanguardia de los valores cooperativos y de los nuevos valores que han de ser asumidos por las cooperativas en tanto en cuanto se identifiquen con ellas, y lo es conveniente que lo haga porque puede, porque es reconocible como realidad, porque tiene implantación a lo largo y ancho del mundo, porque cuenta con los medios para hacerlo y porque lo necesita si quiere posicionarse en el mundo globalizado como movimiento reconocible.

\section{Bibliografía}

\section{Libros y Revistas}

ALCANTARA, L.C.S, SAMPAIO, C.A.C. \& URIARTE, L. 2018. «Experiencia Cooperativa de Mondragón: la educación cooperativa como un proceso de transformación social», CIRIEC-España, Revista de Economía Pública, Social y Cooperativa, 93, 181-209, DOI:10.7203/CIRIEC-E.93.9217.

ARRIETA IDIAKEZ, F.J. 2019. "La colaboración público-privada en el fomento de la economía colaborativa en el ámbito local: una alternativa a la economía informal que trae causa de la falsa economía colaborativa», Lan harremanak: revista de relaciones laborales, $\mathrm{n} .^{\circ} 41$. 
ARRIETA IDIAKEZ, F.J. 2018. "La formación dual en el ámbito universitario como alternativa a los retos planteados por la industria 4.0 en cuanto a la empleabilidad de los jóvenes». En La revolución tecnológica y sus efectos en el mercado de trabajo: un reto del siglo XXI (MELLA MÉNDEZ, L., Dir.). Madrid: La Ley - Wolters Kluwer.

ARRIETA IDIAKEZ, F.J, 2017. «La exclusión social de los jóvenes y las cooperativas», Civitas: Nueva Revista Española de Derecho del Trabajo, n. ${ }^{\circ} 202$.

ARRIETA IDIAKEZ, F.J, LÓPEZ RODRÍGUEZ, J. y MARTíNEZ ETXEBERRIA, G., «¿En qué medida las cooperativas, como entidades de la economía social, ofrecen una protección social adecuada a sus socios?», ponencia defendida en el marco del Congreso conmemorativo del centenario de la OIT, celebrado en Sevilla en el mes de febrero de 2019, pendiente de publicación.

ATXABAL RADA, A. 2020. "Las medidas fiscales para favorecer el emprendimiento por las cooperativas», REVESCO, Revista de Estudios Cooperativos, n. ${ }^{\circ}$ 133. DOI: https://dx.doi.org/10.5209/REVE.67335.

ATXABAL RADA, A. 2018. "Los impuestos personales sobre el capital en las cooperativas y en sus socios en Euskadi», Boletín de la Asociación Internacional de Derecho Cooperativo, n. ${ }^{\circ}$ 52. DOI: http://dx.doi.org/10.18543/ baidc-52-2018pp137-166

ATXABAL RADA, A. 2016. "La identidad cooperativa como justificación de un tratamiento fiscal diferenciado», Boletín de la Asociación Internacional de Derecho Cooperativo, n. ${ }^{\circ}$ 50. DOI: http://dx.doi.org/10.18543/baidc-502016pp285-307

DEL BURGO GARCÍA, U. 2002. «La desnaturalización de las cooperativas», Boletín de la Asociación Internacional de Derecho Cooperativo, n. ${ }^{\circ} 36$. DOI: $^{2}$ http://dx.doi.org/10.18543/baidc-36-2002pp51-120

CARRASCO CARRASCO, M. 1991. "La Empresa Cooperativa actual: ni mutualidad ni ausencia del lucro. La justificación de una protección fiscal», en CIRIEC-España, Revista de Economía Pública, Social y Cooperativa, n. ${ }^{\circ} 14$.

CIURANA FERNÁNDEZ, J. M. 1965. "La esencia de la cooperación».

CRACOGNA, D. 1991. "Reflexiones sobre los valores y los valores cooperativos en la Alianza Cooperativa Internacional», Anuario de Estudios Cooperativos, UD, Bilbao.

CRACOGNA, D. 1994. "La identidad cooperativa en un mundo cambiante», Anuario de Estudios Cooperativos, UD, Bilbao.

DIVAR GARTEIZ-AURRECOA, J. y GADEA SOLER, E. 2002. «Los valores cooperativos y la participación de los trabajadores en la empresa», Boletín de la Asociación Internacional de Derecho Cooperativo, n. ${ }^{\circ} 36$. DOI: http:// dx.doi.org/10.18543/baidc-36-2002pp37-44

DIVAR GARTEIZ-AURRECOA, J. 2016. «Breve estudio de la evolución del pensamiento cooperativo», Revista de estudios cooperativos Deusto, n. ${ }^{\circ} 8$, Bilbao.

DONÉSTEVEZ SÁNCHEZ, G. 2016. «El cooperativismo en Cuba: visión desde la economía crítica», en AAVV, Sector cooperativo y desarrollo local. Visión desde las redes cubanas de investigación, Editorial Feijóo, Santa Clara, Cuba. 
ESTARLICH MARTORELL, V. 2002. «Los valores de la cultura económica cooperativa», Boletín de la Asociación Internacional de Derecho Cooperativo, n. ${ }^{\circ}$ 36. DOI: http://dx.doi.org/10.18543/baidc-36-2002pp121-138

FARÍAS, C.A. 2002. "Valores de la cultura económica cooperativa», Boletín de la Asociación Internacional de Derecho Cooperativo, n. ${ }^{\circ}$ 36. DOI: http:// dx.doi.org/10.18543/baidc-36-2002pp45-50

FERNÁNDEZ PEISO, A. 2012. La cooperativa: bases su legislación en Cuba, Editorial de Ciencias Sociales, Cuba.

$\mathrm{FICl}$, A. 2014. «Valores cooperativos, Derecho cooperativo y jóvenes», Revista de Estudios Cooperativos de Deusto, n. ${ }^{\circ} 4$, Bilbao.

GADEA SOLER, E. 2019. «Estudio sobre el concepto de cooperativa: Referencia a los principios cooperativos y su discutida vigencia», JADO, Boletín de la Academia Vasca de Derecho, n. 17.

GADEA SOLER, E. 2015. «La competencia legislativa en materia cooperativa: el caso espeñol» en ARRIETA IDIAKEZ, F.J, ARNÁEZ ARCE, V.M y IZQUIERDO MUCIÑO M.E (coords.) Aprendizaje cooperativo sin fronteras España-México, Dykinson, Colección de estudios cooperativos, vol.ll, Madrid.

GADEA SOLER, E. 2014. "La regulación española en materia de cooperativas» en GADEA SOLER, E, ATXABAL RADA, A y IZQUIERDO MUCIÑO M.E (Coords) Las cooperativas como alternativa económica: Una visión de México y España, Dykinson, Colección de estudios cooperativos, vol.I, Madrid.

GADEA SOLER, E., SACRISTÁN F. y VARGAS C. 2009. Régimen jurídico de la sociedad cooperativa del siglo XXI: realidad actual y propuestas de reforma. Madrid: Dykinson.

GAMINDE EGIA, E. y MARTÍNEZ ETXEBERRIA, G. 2019. "La formación en valores cooperativos como elemento decisivo en los nuevos empleos a crear por las cooperativas del S.XXI», Boletín de la Asociación Internacional de Derecho Cooperativo, n. ${ }^{\circ}$ 54. DOI: http://dx.doi.org/10.18543/baidc-542019pp97-114

GAMINDE EGIA, E. 2018. «El modelo cooperativo: mucho más que una cooperativa ante la crisis» en ARNÁEZ ARCE, V.M y IZQUIERDO MUCIÑO M.E (Coords) Fomento del cooperativismo como alternativa económica y social sostenible: una visión de México y España, Dykinson, Colección de estudios cooperativos, vol. III, Madrid.

GAMINDE EGIA, E. 2017. "Las altas de los/as socios/as en las sociedades cooperativas», Boletín de la Asociación Internacional de Derecho Cooperativo, n. ${ }^{\circ}$ 51. DOI: http://dx.doi.org/10.18543/baidc-51-2017pp191-208.

INGLADA, M. E., SASTRE CENTENO., J. M. y VILLAROYA LEQUERICAONAINDIA, M. B. 2015. «El cooperativismo en la educación», Revesco, Revista de Estudios Cooperativos, n. ${ }^{\circ} 118$, Madrid.

ISPIZUA ZUAZUA, A. 2002. "Valores cooperativos y gestión pública» Boletín de la Asociación Internacional de Derecho Cooperativo, n. ${ }^{\circ}$ 36. DOI: http:// dx.doi.org/10.18543/baidc-36-2002pp25-35

JULIÁ, J.F., MELIÁ, E. y MIRANDA, E. 2020. «Rol de la economía social y la universidad en orden a un emprendimiento basado en el conocimiento tecno- 
lógico y los valores», CIRIEC-España, Revista de Economía Pública, Social y Cooperativa, 98, 31-57. DOI: 107203/CIRIEC-E.98.15905.

KAPLAN DE DRIMER, A. y DRIMER B. 1981. Las cooperativas. Fundamentos, Historia-Doctrina. Buenos Aires: Intercoop (3. ${ }^{a}$ edición).

LAMBERT, P. 1970. La doctrina cooperativa, Intercoop, Buenos Aires, Argentina.

LARRAZABAL BASAÑEZ, S. 2018. «Calidad democrática, sistema institucional y modelo territorial vasco», Revista de Derecho Político, n. ${ }^{\circ} 103$.

LÓPEZ RODRÍGUEZ, J. 2017. "La promoción del emprendimiento social mediante metodologías innovadoras: hacia un nuevo paradigma educativo», Lan Harremanak, Revista de relaciones laborales, UPV/EHU, n. ${ }^{\circ} 37$ extra.

LÓPEZ RODRÍGUEZ, J. 2019. "The promotion of both decent and green Jobs through cooperatives (La promoción de empleos verdes y decentes a través de cooperativas)», Boletín de la Asociación Internacional de Derecho Cooperativo, n. ${ }^{\circ}$ 54. DOI: http://dx.doi.org/10.18543/baidc-542019pp115-129

MACÍAS RUANO, A.J. 2017. La participación económica del socio: un principio internacional cooperativo de pronóstico reservado, Dykinson, Madrid.

MARCUS, L. 1988. "Cooperatives and Basics Values», ICA, XXIX Congress, Stockholm, July 1988, Agenda \& Reports, ICA, Geneva.

MARTíN CASTRO, M.P. 2013. "Los fondos sociales» en la obra colectiva VÁZQUEZ RUANO, T (Coord.) Tratado de Derecho cooperativo, Tirant Lo Blanch, Valencia.

MARTíNEZ CHARTERINA, A. 2016. La cooperativa y su identidad, Colección Deusto sobre cooperativismo, Ed. Dykinson, Madrid.

MARTÍNEZ CHARTERINA, A. 1995. "Los valores y los principios cooperativos», en REVESCO, Revista de Estudios Cooperativos, n. ${ }^{\circ} 61$.

MARTíNEZ ETXEBERRIA, G. 2014. «La juventud como valor corporativo en las sociedades mercantiles cooperativas del siglo XXI», en Difusión de los valores y principios cooperativos entre la juventud. Madrid: Dykinson S.L.

MARTíNEZ ETXEBERRIA, G. 2018. La aplicación efectiva de los valores cooperativos: un reto educativo para el movimiento cooperativo, Dykinson.

MARTíNEZ ETXEBERRIA, G. y MATA DIESTRO, H. 2018. "Perspectivas para un cooperativismo socialista integral con base en los valores y principios promovidos por la Constitución cubana», en la obra colectiva HERNÁNDEZ AGUILAR, O. y RODRÍGUEZ MUSA, O. (Coords.) Apuntes de Derecho cooperativo, Editorial Loynaz, La Habana-Cuba.

MIRANDA, J. E. 2012. De la crisis de identidad al rescate de la génesis del cooperativismo. Madrid: Dykinson.

MIRANDA, J. E. y CORREA LIMA, A. 2017. «Educación, formación humana y valores cooperativos: una propuesta de revitalización de las prácticas educativas brasileñas para el rescate del hombre social y fraterno», Revista de Estudios Cooperativos Deusto, n. ${ }^{\circ}$ 9, Bilbao.

MLADENATZ, G. 1969. Historia de las doctrinas cooperativas, Buenos Aires: Intercoop. 
MÖLLER, E. 1986. El cooperativismo como proceso de cambio. Doctrina histórica del cooperativismo. Bolivia: Editorial Los Amigos del Libro.

OROZCO VÍLCHEZ, J. 1997. Doctrina cooperativa, UNED, 1997.

PASTOR SEMPERE, C. 2001. «El régimen económico: principales aspectos» en ALONSO ESPINOSA, F. J. (Coord) La sociedad cooperativa en la Ley 16/1999, de 16 de julio, Editorial Comares, Granada.

PRIETO PADÍN, P. 2016. «Adquisición de competencias profesionales de los estudiantes de formación profesional y universitarios mediante la combinación de experiencia (pre)laboral y formación práctica», en AAVV (FERNÁNDEZ FERNÁNDEZ, R., Dir. y ÁlVAREZ CUESTA, H., (Coord.): Empleo juvenil: un reto para Europa («Youth employment: a challenge for Europe»), Cizur Menor (Aranzadi).

PUYO ARLUCIAGA, A. M. 2014. "La nueva normativa cubana de cooperativas no agropecuarias, Revista Vasca de Economía Social», GEZKI, n. ${ }^{\circ} 11$.

ROSEMBURG, T. 2002. "El valor del socio en la cultura cooperativa», Boletín de la Asociación Internacional de Derecho Cooperativo, n. ${ }^{\circ} 36$. DOI: http:// dx.doi.org/10.18543/baidc-36-2002pp15-23

SLEE, T. 2016. Lo tuyo es mío: contra la economía colaborativa», Taurus.

URIBE GARZÓN, C. 2001. Bases del cooperativismo, Editorial Guadalupe, Colombia. VAQUERO SÁNCHEZ, J. M. 2015. "Análisis crítico de la cooperación: el caso de la empresa cooperativa», Revista de Estudios Cooperativos de Deusto, n. ${ }^{\circ} 6$, Bilbao.

\section{Legislación}

Constitución Española, publicada en el BOE n. ${ }^{\circ} 311$, de 29 de diciembre de 1978.

Ley 12/1981, de 13 de mayo, del Concierto Económico con la Comunidad Autónoma del País Vasco, publicada en el $B O E, \mathrm{n}$. $^{\circ} 127$, de 28 de mayo de 1981

Ley 4/1993, de 24 de junio, de Cooperativas de Euskadi, publicada en el BOPV n. ${ }^{\circ} 135$, de 19 de julio de 1993.

Ley 27/1999, de 16 de julio, de Cooperativas, publicada en el BOE n. ${ }^{\circ} 170$, de 19 de julio de 1999.

Ley 5/1998, de 18 de diciembre, de cooperativas de Galicia, publicada en el $B O E \mathrm{n} .^{\circ} 72$ de 25 de marzo de 1999.

Ley 12/2002, de 23 de mayo, por la que se aprueba el Concierto Económico con la Comunidad Autónoma del País Vasco publicada en el BOE n. ${ }^{\circ} 124$, de 24 de mayo de 2002.

Ley 6/2008, 25 junio, de la Sociedad Cooperativa Pequeña de Euskadi, publicada en el BOPV n. ${ }^{\circ} 127$, de 4 de julio de 2008.

Ley del Principado de Asturias 4/2010, de 29 de junio, de cooperativas, publicada en el $B O E$ n. ${ }^{\circ} 232$ de 24 de septiembre.

Ley 14/2011, de 23 de diciembre, de sociedades cooperativas andaluzas, publicada en el BOE n. ${ }^{\circ} 17$ de 20 de enero de 2012. 
Ley $6 / 2013$, de 6 de noviembre, de cooperativas de Cantabria, publicada en el $B O E$ n. ${ }^{\circ} 284$, de 27 de noviembre de 2013.

Norma Foral 11/2013, del Impuesto de Sociedades, de 5 de diciembre, publicada en el BOB n. ${ }^{\circ} 238$, de 13 de diciembre de 2013.

Ley $9 / 2018$, de 30 de octubre de cooperativas de Extremadura, publicada en el $B O E$ n. ${ }^{\circ} 289$, de 30 de noviembre de 2018.

\section{Otras fuentes}

Declaración de la ACI sobre la Identidad Cooperativa adoptada por la II Asamblea General de la Alianza Cooperativa Internacional en septiembre de 1995 en Manchester con motivo del Centenario de la Alianza Cooperativa Internacional. 


\section{Derechos de autor}

El Boletín de la Asociación Internacional de Derecho Cooperativo es una revista de acceso abierto lo que significa que es de libre acceso en su integridad inmediatamente después de la publicación de cada número. Se permite su lectura, la búsqueda, descarga, distribución y reutilización legal en cualquier tipo de soporte sólo para fines no comerciales y según lo previsto por la ley; sin la previa autorización de la Editorial (Universidad de Deusto) o el autor, siempre que la obra original sea debidamente citada (número, año, páginas y DOI si procede) y cualquier cambio en el original esté claramente indicado.

\section{Copyright}

The International Association of Cooperative Law Journal is an Open Access journal which means that it is free for full and immediate access, reading, search, download, distribution, and lawful reuse in any medium only for non-commercial purposes, without prior permission from the Publisher or the author; provided the original work is properly cited and any changes to the original are clearly indicated. 